\title{
Penggunaan e-KTP untuk Registrasi Otomatis Memanfaatkan Sistem OCR Dengan Metode Template Matching Correlation
}

\author{
Siti Sarah Abdullah ${ }^{1}$, Fadhil Dzikri Muhammad ${ }^{2}$ \\ Teknik Informatika, Universitas Suryakancana \\ Sarah0040057@gmail.com ${ }^{1}$,Fadhil.dzikri@gmail.com²
}

\begin{abstract}
E-KTP (I.D. Card) as identity of Indonesian residence has been optimally yet, for example projected to evoting on elections or tax necessity. Actually, record of identity on I.D. card could be useful for other. Researched will identified for data retrieval with Optical Character Recognition (OCR). Method on research used Template Matching Correlation. Data from I.D. Card changed to *.bmp or *.jpg format, then scanned with OCR and do normalization. The result from researched is identity of residence automatically input to registration application without typed it to application.
\end{abstract}

Keywords: OCR, e-KTP, Registration, Template Matching Correlation

\begin{abstract}
Abstrak
E-KTP (Kartu Tanda Penduduk Elektronik) sebagai identitas jati diri tunggal Penduduk Indonesia, masih belum dimanfaatkan secara optimal, misalnya baru diproyeksikan untuk e-voting saat pemilu dan kebutuhan pajak. Rekaman identitas penduduk yang tertanam dalam chips dalam e-KTP, dapat dimanfaatkan untuk hal lain. Penelitian mengidentifikasi pengambilan data dengan memanfaatkan teknologi Optical Character Recognition (OCR) Android. Metode yang digunakan dalam penelitian yaitu metode Template Matching Correlation. Data dari e-KTP diubah kedalam format *.bmp atau *.jpg, kemudian dilakukan pemindaian dengan OCR, kemudian dinormalisasi. Hasil yang diperoleh yaitu identitas penduduk sesuai data yang terdapat dalam e-KTP, dan otomatis masuk kedalam aplikasi registrasi tanpa mengetik ulang.
\end{abstract}

Kata kunci: OCR, e-KTP, Registrasi, Template Matching Correlation

\section{Pendahuluan}

Semua aplikasi yang didalamnya terdapat transaksi, diperlukan registrasi terlebih dahulu. Hasil observasi yang dilakukan di beberapa aplikasi marketplace seperti Tokopedia, shopee, dan sebagainya, untuk melakukan registrasi diperlukan mengetikkan identitas, kemudian mengunggah KTP, kemudian menunggu untuk diverifikasi mengenai kecocokan data antara KTP dengan data yang dimasukkan. Hal tersebut tentu memakan waktu. Apalagi jika banyak yang melakukan registrasi dengan waktu berdekatan atau bersamaan. Padahal, didalam e-KTP terdapat chips yang didalamnya berisi identitas / jati diri penduduk. Fasilitas dalam eKTP masih belum banyak yang memanfaatkan.

Efisiensi dan efektifitas dalam registrasi, dengan memanfaatkan teknologi yang sekarang sudah ada atau sedang berkembang, memungkinkan registrasi dilakukan secara otomatis dengan memanfaatkan e-KTP. E-KTP yang ada diusulkan untuk di pindai menggunakan Optical Character Recognition (OCR), dengan harapan registrasi dapat dilakukan secara otomatis.

\section{Landasan Teori}

Beberapa teori yang terkait dengan penelitian diantaranya OCR, template matching correlation, e-KTP.

\subsection{Optical Character Recognitoin (OCR)}

Optical Character Recognition (OCR) merupapkan konversi gambar huruf menjadi karakter ASCII yang dikenali oleh komputer. Gambar huruf yang dimaksud dapat berupa hasil scan dokumen, hasil print screen halaman web, hasil foto, dan lain sebagainya [1].

Modul dalam sistem OCR terdiri dari akuisisi gambar (image acquisition) berisi citra berbentuk teks yang berasal dari hasil pemindaian atau citra yang telah disimpan dalam komputer. Disebut citra karena hasil pemindaian, sekalipun berisi teks namun hasil pemindaian bukan berupa karakter; pra-proses (preprocessing) menurut [1] berdasarkan [2] bermanfaat untuk menghaluskan karakter digit; ekstraksi fitur (feature extraction) merupakan proses mendapatkan informasi tentang objek atau grup objek dalam rangka memfasilitasi klasifikasi. Citra yang telah direkam kemudian dibandingkan dengan menggunakan modul 
template matching yaitu membuat gambar menjadi bentuk biner [2]; dan perubahan pola (pattern generate) yaitu men-generate pixel dengan cara mengidentifikasi jumlah pixel yang terbagi kdalam sektor dan track [1]. Diagram blok sistem OCR dapat dilihat pada gambar 1.

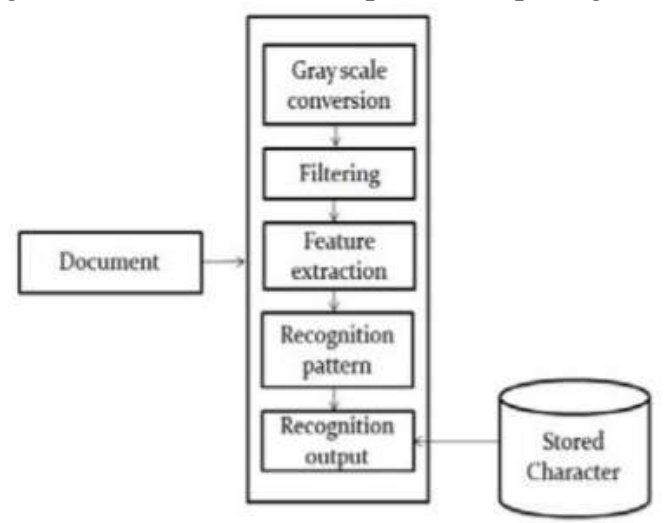

Gambar 1 Diagram Blok Sistem OCR [1]

\section{2 e-KTP}

KTP elektronik (KTP-el / e-KTP) merupakan dokumen kependudukan yang memuat system keamanan / pengendalian baik dari sisi administrasi maupun teknologi informasi dengan berbasis pada basis data kependudukan nasional. Struktur e-KTP terdiri dari 9 (sembilan) layer yang akan meningkatkan pengaman dari KTP konvensional. Chips ditanam diantara plastik putih dan transparan pada dua layer tertas. Chips ini memiliki antena didalamnya yang akan mengeluarkan gelombang jika digesek. Gelombang inilah yang akan dikenali oleh alat pendeteksi e-KTP sehingga dapat diketahui apakah KTP tersebut berada ditangan yang benar atau tidak. EKTP dilindungi dengan keamanan pencetakan seperti relief text microtext, filter image, invisible ink dan warna yang berpendar dibawah sinar ultraviolet serta anti copy design.

Informasi yang tercantum dalam e-KTP yaitu: Nomor Induk Kependudukan; Nama Lengkap; Tempat Tanggal lahir; Jenis Kelamin; Agama; Status; Golongan Darah; Alamat Lengkap; Pekerjaan; Pas foto; Tempat dan tanggal dikeluarkannya KTP; tandat tangan pemegang Ktp; nama dan momor induk pegawai pejabat yang menandatanganinya [3].

\subsection{Template Matching Correlation}

Template matching merupakan teknik dalam pemrosesesan citra digital untuk menemukan bagian kecil dari gambar yang sesuai dengan template gambar [4]. template tersebut yang menjadi pola. Pada template matching, citra yang telah diinput dibandingkan dengan citra template yang berada pada basis data kemudian dibandingkan dengan menggunakan aturan tertentu [5]. kesamaan antar dua matriks dapat dihitung nilainya dengan menggunakan korelasi (correlation) yang didapat dengan menghitung rumus [5]:

$$
r=\frac{\sum_{k=1}^{n}\left(x_{i k}-\bar{x}_{i}\right) \cdot\left(x_{j k}-\bar{x}_{j}\right)}{\sqrt{\left[\sum_{k=1}^{n}\left(x_{i k}-\bar{x}_{i}\right)^{2} \cdot \sum_{k=1}^{n}\left(x_{j k}-\bar{x}_{j}\right)^{2}\right]}}
$$

Dimana:

$$
\begin{aligned}
& \bar{x}_{i}=\frac{1}{n} \sum_{k=1}^{n} x_{i k} \\
& \bar{x}_{j}=\frac{1}{n} \sum_{k=1}^{n} x_{j k}
\end{aligned}
$$

Keterangan:

$r$ : nilai korelasi antara dua buah matriks (nilainya antara -1 dan +1$)$

xik : nilai pixel ke-k dalam matriks i

$x j k$ : nilai pixel ke-k dalam matriks $\mathrm{j}$

$\mathrm{xi}$ : rata-rata nilai pixel matriks $\mathrm{i}$

$\mathrm{xj}$ : rata-rata nilai pixel matriks $\mathrm{j}$

n : jumlah pixel dalam suatu matriks

\section{Metode}

Metode penelitian diantaranya: melakukan observasi, analisis dan perancangan, dan implementasi sebagaimana dapat dilihat pada Gambar 2.

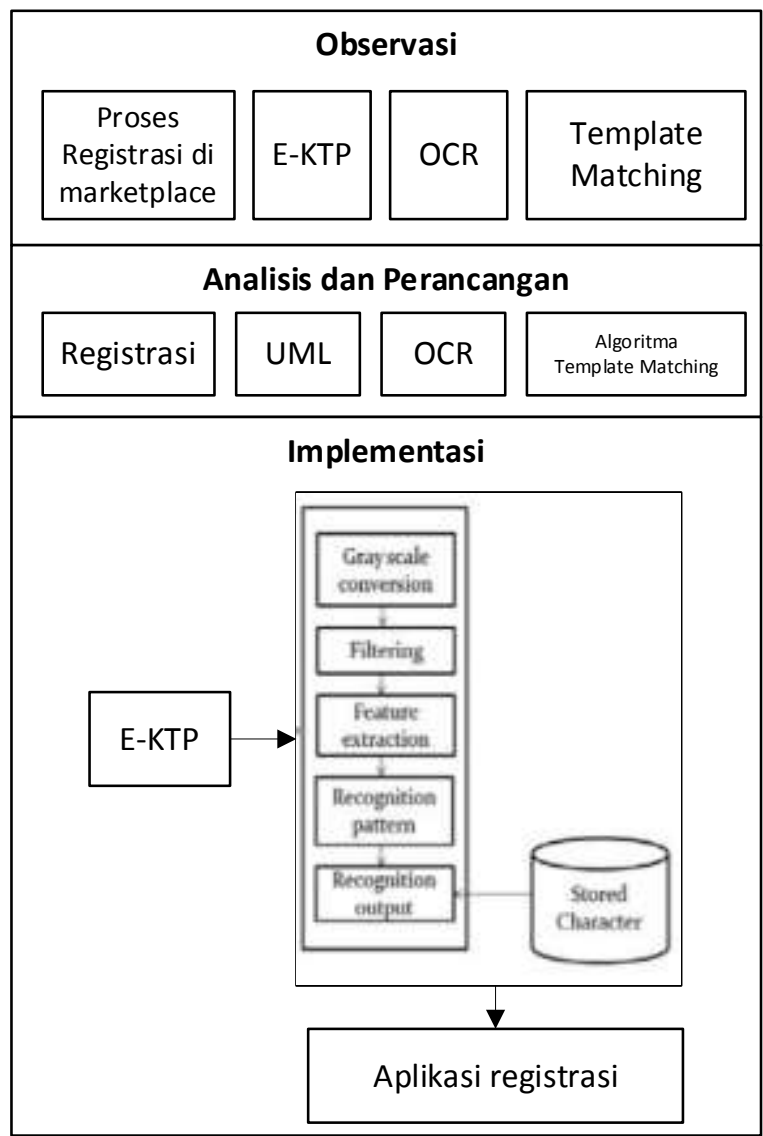

\section{Gambar 2. Metode pemindaian e-KTP dengan OCR} untuk registrasi

Berdasarkan Gambar 2, observasi yang dilakukan adalah mengidentifikasi proses registrasi di beberapa marketplace, mengidentifikasi konten yang terdapat dalam e-KTP, mengidentifikasi mengenai OCR, dan mengidentifikasi proses template matching. Tahap berikutnya adalah melakukan analisis dengan perspektif as is dan to be. Analisis as-is yaitu melihat beberapa registrasi yang dilakukan, dan ide penerapan registrasi yang akan dibuat, kemudian dibuat model dengan 
menggunakan UML. Hasil dari perancangan diimplementasikan dengan hasil akhir yang diharapkan adalah tampil identitas penduduk dalam registrasi tanpa mengetikkan identitas.

\section{Hasil dan Pembahasan}

Berdasarkan observasi yang dilakukan, registrasi dibuat berdasarkan hasil input yang dilakukan oleh pengguna. Sebagai contoh, dalam salah satu marketplace, identitas pengguna dimasukkan melalui pengetikkan, kemudian mengunggah e-KTP. Pengguna harus menunggu untuk verifikasi apakah data yang dimasukkan sesuai dengan KTP yang diunggah. Tentu saja hal tersebut memakan waktu, karena proses verifikasi tidak dapat dilakukan secara langsung. Observasi berikutnya adalah mengidentifikasi kemungkinan data e-KTP untuk dipindai dengan OCR, dengan melihat kemungkinan data yang terdapat dalam e-KTP bisa ditangkap. Tahapan OCR di cocokkan dengan algoritma template matching correlation.

Tahapan analisis dan perancangan adalah mengidentifikasi registrasi agar dapat dilakukan secara otomatis. Pemodelan untuk analisis dan perancangan dilakukan dengan menggunakan UML. Salah satu model yang menggambarkan sistem secara umum yaitu use case diagram sebagaimana dapat dilihat pada gambar 3 .

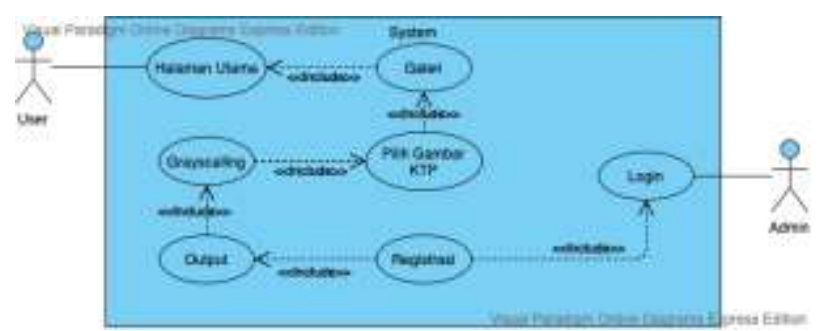

Gambar 3. Use Case Diagram Registrasi Otomatis

Tahap implementasi yaitu membuka aplikasi registrasi dengan tampilan default disable. Aplikasi akan mengarahkan untuk meng-klik kamera atau mengambil foto KTP yang telah tersimpan didalam komputer, kemudian citra yang ditangkap akan dilakukan proses OCR sebagaimana dibahas dalam subbab 3, yaitu terdapat proses grayscaling, filtering, feature extraction, recognition pattern, recognition output. identitas KTP yang telah diproses tadi, akan masuk secara otomatis ke aplikasi registrasi tanpa harus mengetikkan. Hasil akhir yang didapat yaitu akan muncul identitas pengguna secara otomatis (tanpa mengetikkan) sesuai dengan data yang terdapat didalam e-KTP.

Sub bab 4.1 sampai 4.7 merupakan langkah implementasi dari penelitian yang dilakukan.

\subsection{Tampilan Awal Registrasi}

Tampilan awal aplikasi registrasi menampilkan nilai default dengan disable, dan aplikasi mengarahkan untuk meng-klik 'galeri'. Sebagai contoh, data yang dimasukkan dalam registrasi yaitu data identitas pengguna sesuai dengan KTP, seperti ditampilkan dalam Gambar 4.
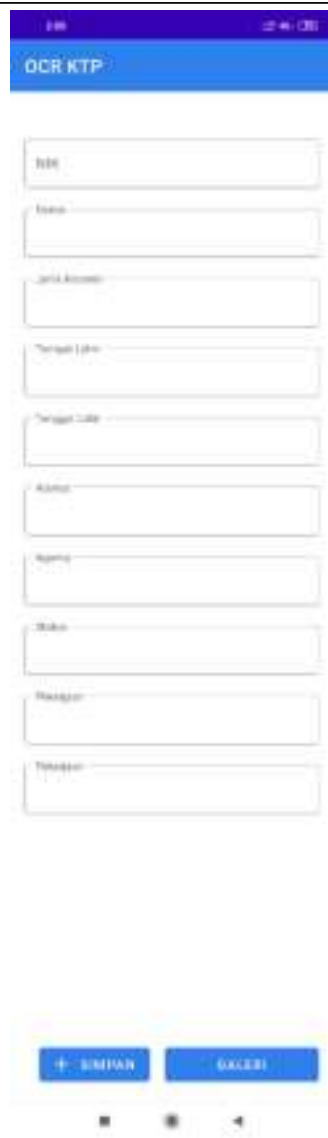

Gambar 4. Aplikasi Registrasi

\subsection{Penangkapan Citra}

KTP difoto dengan posisi sesuai petunjuk kamera. Hasil akhirnya adalah citra dalam bentuk *.jpg atau *.bmp, sebagai sampel, dipilihkan NIK untuk contoh kasus, seperti yang terlihat dalam gambar 5 .

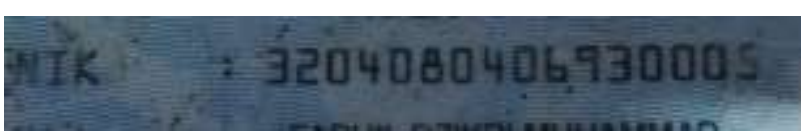

Gambar 5. Citra asli

\subsection{Grayscale Conversion}

Citra asli kemudian dilakukan perubahan warna menjadi hitam putih, seperti tampak pada gambar 6 .

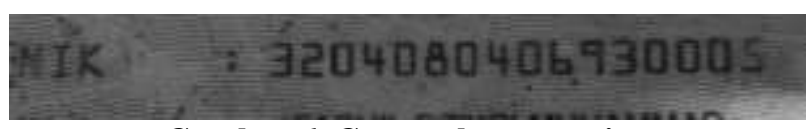

Gambar 6. Grayscale conversion

\subsection{Filtering}

Citra yang telah diubah warna kemudian dilakukan penghilangan objek yang tidak dibutuhkan, dan melakukan perubahan warna menjadi hitam dan putih, seperti terlihat pada gambar 7 .

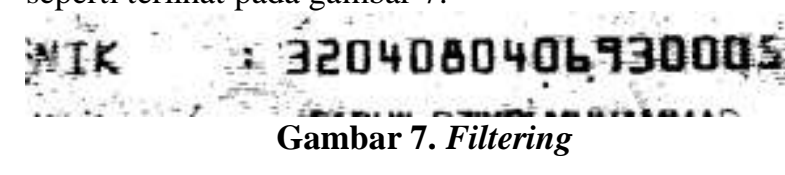




\subsection{Feature Extraction}

Hasil filtering dipotong per-karakter, kemudian menormalisasi ukuran pixel, dan menterjemahkan data pixel kedalam nilai biner.

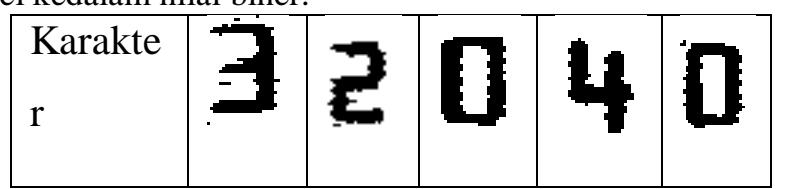

Gambar 8. Normalisasi

\subsection{Recognition Pattern}

Proses recognition pattern yaitu menggunakan metode template matching recognition, yaitu membuat pola (template) dengan citra yang ada dengan membagi angka biner menjadi 5 track, dimana setiap track memiliki 8 sektor sebagaimana dilihat pada gambar 8 .

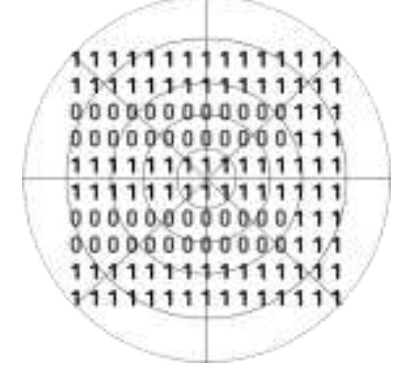

Gambar 8. contoh pattern

\subsection{Recognition Output}

Matriks biner yang terdapat pada gambar 8 dan telah menjadi biner kemudian disesuaikan dengan template, dan dibandingkan dengan data font yang terdapat dalam database.

Hasil akhir kemudian dimasukkan secara otomatis kedalam aplikasi registrasi sebagaimana dapat dilihat pada gambar 9 .

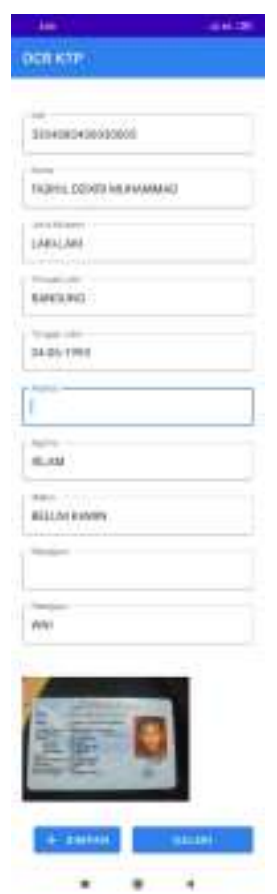

Gambar 9. Hasil Luaran

\section{Simpulan}

Berikut simpulan dari hasil penelitian yang telah dilakukan:

a. Tingkat keberhasilan memindai identitas yang terdapat dalam e-KTP dengan memanfaatkan OCR berhasil $85 \%$. b. Dalam implementasinya, identitas masih belum dapat dibaca semua, yaitu alamat. Data hasil pemindaian, alamat terbaca tidak sesuai yang diharapkan. Masih perlu dilakukan penelitian lanjut.

\section{Daftar Pustaka}

[1] F. Mohammad, J. Anarase, M. Shingote and P. Ghanwat, "Optical Character Recognition Implementation using Pattern Matching," International Journal of Computer Science and Information Technologies (IJCSIT), vol. 5, no. 2, pp. 2088-2090, 2014.

[2] M. Nallasamy and S. Bala, "Applicaion of Artificial Neural Network Model for Optical Character Recognition," IEEE Computer, 1997.

[3] Peraturan Presiden No. 26 Tahun 2009, "Penerapan Kartu Tanda Penduduk Berbasis Nomor Induk Kependudukan secara Nasional," Jakarta, 2009.

[4] R. Brunelli, Template Matching Techniques in Computer Vision: Theory and Practice, Wiley, 2009.

[5] S. Hartanto, A. Sugiharto and S. N. Endah, "Optical Character Recognition menggunakan Algoritma Template Marching Correlation," Journal of Informatics and Technology, vol. 1, no. 1, pp. 11-20, 2012. 